\title{
Supporting people who care for older family members
}

\author{
Jasneet Parmar MBBS, Nathalie Jette MD MSc, Suzette Brémault-Phillips PhD, Jayna Holroyd-Leduc MD
}

I n Canada, there are an estimated four million people caring for older family members with short- or long-term health conditions. ${ }^{1}$ A recent Canadian study estimated the cost of such unpaid caregiving at $\$ 25$ billion. $^{2}$ Global costs of informal care related just to dementia are estimated to be a staggering $\$ 252$ billion of the $\$ 604$ billion in societal costs. ${ }^{3}$

Family caregivers are an integral, yet increasingly overburdened, group providing care within our health care system. Defined by the World Health Organization as those who provide informal unpaid care, ${ }^{3}$ family caregivers contribute immeasurably to the support of vulnerable older adults. However, this is not without physical, emotional and financial costs to the caregiver. ${ }^{4}$ Time pressures, financial concerns and childcare issues can be overwhelming. Given the essential role of caregivers within the health care system, supporting them has become a global public health priority.

Many older Canadians with complex health conditions are receiving limited hours of publicly funded home care services and therefore rely on family caregivers. ${ }^{5}$ As a result, a large number of family caregivers are stretched beyond their capacity and report high levels of stress. ${ }^{5}$ According to a 2012 Canadian survey, most caregivers are between 45 and 64 years of age and typically spend three or more hours per week providing care to older family members. ${ }^{6}$ The most common types of care include transportation, house cleaning, meal preparation, house maintenance and outdoor work. More than one-quarter of caregivers are "sandwiched" between caring for parents and raising children. ${ }^{6}$ Overall, $28 \%$ of caregivers said they would like more assistance, financial or otherwise. ${ }^{6}$ The increasing size of older populations worldwide raises concerns about the continued ability of families to provide the level of care needed to allow older adults to remain in their own homes.

Many older adults prefer to live at home for as long as possible. ${ }^{5}$ However, the burden on and the distress among family caregivers is ever increasing. These effects are particularly evident among those who provide more than 21 hours of care per week and those who support older adults with depression, moderate to severe cognitive decline or aggressive behaviour. ${ }^{7}$ The challenges associated with supporting individuals with these types of conditions add to the strain on and wear down the resilience of caregivers. People who care for family members with life-limiting conditions have the added stress and emotions associated with losing a loved one. These factors place caregivers at risk of being compromised themselves.

With the multiple challenges faced by caregivers, ${ }^{4}$ the result may be a deterioration of the caregiver's physical and mental health, social isolation, family conflict and lost income. ${ }^{4,8}$ In the 2012 survey, $46 \%$ of caregivers caring for spouses and $30 \%$ of those caring for parents reported at least five symptoms of psychological distress, such as depression, feelings of isolation and disturbed sleep. ${ }^{6}$ It has been reported that caregivers who feel more burdened and distressed while providing support have more difficulties adjusting during bereavement. ${ }^{4}$ Caregiver stress may also increase the risk of elder abuse. ${ }^{9}$ Therefore, caregivers require support from the health, social, financial and legal systems to ensure that they can continue to provide care while maintaining their own well-being.

Various types of caregiver support have been evaluated. One systematic review suggested that respite care, individual and group caregiver support, and technology-based interventions may be helpful. ${ }^{10}$ Factors that can affect the success of interventions include the degree of caregiver involvement, the extent to which programs are individualized, access to information and coaching, and the type and impact of the behaviour of the care recipient. ${ }^{11}$ An array of evidence-based programs for caregivers of family members with dementia exists, from counselling and skills training to telephone- and Internet-based service delivery
Competing interests: None declared.

Disclaimer: Jayna

Holroyd-Leduc is an Associate Editor of CMAJ and was not involved in the editorial decision-making process for this article.

This article was solicited and has not been peer reviewed.

Correspondence to: Jayna Holroyd-Leduc, jayna.holroyd-leduc @ albertahealthservices.ca

CMAJ 2014. DOI:10.1503 /cmaj.131831 
systems. However, these programs are currently not widely available. ${ }^{3}$ There is a gap between what the evidence shows to be beneficial and what is currently available to most caregivers.

The G8 health ministers recently met at the Dementia Summit in London, United Kingdom, to discuss how to shape an effective international response to dementia, which will need to include appropriate support for people with dementia and their family caregivers. ${ }^{12}$ Canada has agreed to play a role in addressing this important global health issue.

Canada has a federal caregiver tax credit; however, only $5 \%$ of caregivers providing care to their parents reported receiving this tax credit. ${ }^{6}$ The support available to family caregivers also varies by province. Some other support currently available includes Internet-based resources, such as those provided by the Alzheimer Society of Canada. However, further ways to foster the resilience and strength of caregivers so that they can maintain a supportive presence are critical to the sustainability of the Canadian health care system. The provision of adequate evidencebased support for family caregivers needs to be an important part of regional, provincial, national and international strategies for the care of older adults and those with dementia.

\section{References}

1. Turner A, Findlay L. Informal caregiving for seniors. Health Rep 2012;23:33-6.

2. Hollander MJ, Liu G, Chappell NL. Who cares and how much? The imputed economic contribution to the Canadian healthcare system of middle-aged and older unpaid caregivers providing care to the elderly. Healthc $Q 2009 ; 12: 42-9$.

3. World Health Organization (WHO); Alzheimer's Disease International. Dementia: a public health priority. Geneva (Switzerland): WHO; 2012.

4. Stajduhar K, Funk L, Toye C, et al. Part 1: Home-based family caregiving at the end of life: a comprehensive review of published quantitative research (1998-2008). Palliat Med 2010;24: 573-93.

5. Seniors in need, caregivers in distress: What are the home care priorities for seniors in Canada? Toronto (ON): Health Council of Canada; 2012.

6. Statistics Canada. Study: caregivers in Canada, 2012. The Daily 2013 Sept. 10. Catalogue no. 11-001-X. Available: www.statcan gc.ca/daily-quotidien/130910/dq130910a-eng.htm (accessed 2014 Jan. 9).

7. Supporting informal caregivers - the heart of home care. Ottawa (ON): Canadian Institute for Health Information (CIHI); 2010.

8. Longo CJ, Fitch M, Deber RB, et al. Financial and family burden associated with cancer treatment in Ontario, Canada. Support Care Cancer 2006; 14:1077-85.

9. Poole C, Rietschlin J. Intimate partner victimization among adults aged 60 and older: an analysis of the 1999 and 2004 General Social Survey. J Elder Abuse Negl 2012;24:120-37.

10. Lopez-Hartmann M, Wens J, Verhoeven V, et al. The effect of caregiver support interventions for informal caregivers of community-dwelling frail elderly: a systematic review. Int J Integr Care 2012;12:e133.

11. Parker D, Mills S, Abbey J. Effectiveness of interventions that assist caregivers to support people with dementia living in the community: a systematic review. Int J Evid-Based Healthc 2008; 6:137-72.

12. G8 Dementia Summit declaration. London (UK): Department of Health, Prime Minister's Office; 2013. Available: www.gov.uk /government/uploads/system/uploads/attachment_data/file/265869 /2901668_G8_DementiaSummitDeclaration_acc.pdf (accessed 2014 Jan. 9).

Affiliations: Departments of Family Medicine (Parmar) and Occupational Therapy (Brémault-Phillips), University of Alberta, Edmonton, Alta.; Departments of Clinical Neurosciences (Jette), Community Health Sciences (Jette, HolroydLeduc) and Medicine (Holroyd-Leduc), University of Calgary, Calgary, Alta.

Contributors: All of the authors contributed substantially to the conception of the manuscript. Jasneet Parmar and Jayna Holroyd-Leduc drafted the article, and Nathalie Jette and Suzette Brémault-Phillips revised it critically for important intellectual content. All of the authors approved the final version submitted for publication and agreed to act as guarantors of the work.

Acknowledgements: Jasneet Parmar receives salary support as the Medical Director of the Covenant Health Network of Excellence in Seniors Health and Wellness. Nathalie Jette has a Canada Research Chair in Neurological Health Services Research and a Population Health Investigator Award from Alberta Innovates - Health Solutions. Jayna Holroyd-Leduc receives salary support as the Scientific Director of the Alberta Health Services Seniors Health Strategic Clinical Network.

The authors thank Tarun Dua from the World Health Organization for her contributions to this commentary. 